\title{
Out-of-borough placements for people with learning disabilities
}

\author{
Sujeet Jaydeokar \& Jack Piachaud
}

Abstract All people with learning disabilities should be able to choose from a variety of residential placements as a way of achieving greater community integration. However, many are still placed away from their borough of origin, resulting in complex consequences for them, and their families and for clinicians. This article explores the nature of the problem, defining the current issues, and examining the role of the stakeholders and the implications for psychiatrists working in this field.

The White Paper Valuing People (Department of Health, 2001) proposes many positive developments for people with learning disabilities in housing, occupation and health. No matter the degree or complexity of their impairments, all people have a right to their own home, with supported-living arrangements as needed. They should also have full access to local mainstream health services. The principle of normalisation, as expressed by Nirje, requires:

'Making available to all mentally retarded people patterns of life and conditions of everyday living which are as close as possible to the regular circumstances and ways of life of society' (quoted in Myers et al, 1998).

This means living in ordinary houses, adapted if necessary, making use of community facilities, being able to stay close to family and friends, and above all having reasonable choices available.

Despite this, responsible local authorities continue to place a significant number of people with learning disabilities in residential care distant from their borough of origin, because of a lack of local options. Some boroughs become seen as 'exporters' and others as 'importers' of people with complex needs. The group of people most likely to be in out-ofborough placements are those with mental health and behavioural problems, and their placement has particular significance for clinicians in both exporting and importing boroughs. In this article we use the term 'borough' to denote the area of a local authority, whether it be urban or rural.

\section{History}

The stigma associated with learning disability goes back to the earliest records. From the mid-1800s, people with learning disabilities who could not be cared for at home were moved to distant institutions, and in the late 1800s the Eugenics movement led to further segregation (Radford, 1991). However, in 1957 a Royal Commission recommended radical changes for mental health services in the UK, with a new emphasis on community care. This shift of care gained further momentum for learning disability following the White Paper Better Services for the Mentally Handicapped (Department of Health and Social Security, 1971). The Jay Committee proposed a model of residential services for people with learning disabilities in local communities: they would live in ordinary houses, adapted as necessary, and staff would work in a flexible manner to meet their needs (Department of Health and Social Security, 1979). This model of care was developed in the King's Fund report An Ordinary Life (King's Fund, 1980).

The years from 1980 to 1990 saw some closure of institutions and a few innovative service developments (Lowe \& de Paiva, 1991). Pressure groups - networks of professionals, parents and service users - all tried to influence the model of services for people with learning disabilities, mainly advocating the principle of normalisation (Holt et al, 2000). But there was still pressure from local communities wanting learning-disabled people to be placed

Sujeet Jaydeokar is a specialist registrar in the psychiatry of learning disabilities with Hertfordshire Partnership NHS Trust (St Peters' House, 2 Bricket Road, St Albans, Hertfordshire AL1 3JW, UK). His research interests include the descriptive psychopathology and forensic issues of learning disabilities. Jack Piachaud is the Clinical Director of the Eric Shepherd Unit in Watford, Hertfordshire. He was the Medical Director of Horizon NHS Trust between 1998 and 2002 , and has been a consultant psychiatrist in learning disabilities since 1981 and an honorary senior lecturer at St Mary's and Imperial College London since 1987. 


\section{Box 1 Structure of learning disability services} in England

Local authorities (social services) and health services, in partnership with learningdisabled individuals, are jointly responsible for providing comprehensive services for people with learning disabilities. Wide variation is seen in the delivery of such services.

Primary care trusts are responsible for the planning, commissioning and, if required, purchasing of services, including social/ residential care and primary health care, for people with learning disabilities.

NHS mental health care trusts provide community and in-patient secondary and tertiary mental health services to the general population. For people with learning disabilities these services are either delivered directly by primary care trusts or purchased by primary care trusts but delivered by NHS mental health care trusts and/or private-sector hospitals.

away from population centres: the concept of Nimbyism (an acronym from 'not in my back yard') became prominent (Foster \& Roberts, 1998). The 1990s saw an accelerating programme of institutional closures and the development of new community placements.

The issue of people with learning disabilities being placed outside their borough of origin is therefore not a new one. During the period of hospital closures there were hopes that community care would increase the availability of local residential care. This has indeed happened, to the advantage of many people, but there are some areas of the country and some specific groups of people that have not benefited from the new developments. A brief outline of leanring disability services is given in Box 1.

\section{The nature of the problem}

In England in 2003, there were 40335 people with learning disabilities who were supported by local authorities and living in residential or nursing care placements (37 985 in residential placements and 2350 in nursing care placements). Of these, $24.6 \%$ of the residential placements and $29.2 \%$ of the nursing care placements were outside the borough of origin (Department of Health, 2003). Data from the 1991 census show that there is a substantial regional and national variation in service provision (Emerson
\& Hatton, 1998). For example, Devon County Council had 265 people in supported residential or nursing care and none of these placements was out of borough (Department of Health, 2003), whereas a slightly earlier survey of London boroughs (National Health Service Executive, 2000) found that up to $80 \%$ of people were placed out of borough.

These figures do not include placements purchased by health authorities, and this information is hard to come by. Although a small number of people still remain in long-stay hospitals, some have been moved from the hospitals into residential care run by the national health service (NHS). Some are placed in private-sector hospitals because there is a lack of beds for short-term admission to NHS hospitals and of local secure hospital placements. Nursing homes care for two distinct groups: those with profound and multiple physical disabilities requiring high levels of physical nursing care, and those with mental health problems requiring psychiatric nursing care. There are no national data on the proportion of these types of need, and local use varies greatly. There has been an increase in the number of registered nursing homes for people with learning disabilities over the past decade (Department of Health, 2002). Local authorities, in partnership with health authorities, should produce the criteria that determine the use of nursing homes as opposed to residential care. In practice, however, for those with complex behavioural or mental health needs there appears to be a blurring of the boundary between robust and coping residential care and nursing homes. Decisions seem to be made pragmatically on the basis of factors such as availability, costs and sources of funding.

The proportion of out-of-borough services purchased appears to be related to the volume of local accommodation and the competence of local services in managing complex needs. Political and economic factors influence both of these factors (Ryan, 1998). It is noticeable that exporting boroughs tend to include city areas where house prices are high. This makes the acquisition of special needs housing expensive and may lead to greater resistance from local pressure groups and politicians who fear a negative effect on house prices. Such areas may espouse the older belief that rural quietness far from the hurly-burly of modern urban living is beneficial for disabled people. The importing boroughs are mainly the Shires, rural areas where large properties are less expensive and there is less likelihood of local opposition being organised. Many of the long-stay hospitals were situated away from population centres, and skilled staff were concentrated in these areas. With the closure of these hospitals, many staff left to run residential homes and services in the same area. 
The problem also seems to be linked to the shortage of beds for short-term admissions to NHS hospitals and the difficulties in moving people through these beds into appropriate long-term accommodation. If there are no in-patient beds then those with behavioural or mental health problems are likely to be placed directly out of the borough. Even if there are beds, pressure to admit causes patients to be discharged into residential provision out of borough, rather than allowing them to remain in hospital until a local solution emerges. A new group of segregated people has appeared, those with dual diagnosis who, 20 years ago, might have gone to a distant NHS hospital but now are being sent to even more distant private-sector providers.

\section{Stakeholders}

\section{People with learning disabilities}

The White Paper Valuing People (Department of Health, 2001) promotes 'person-centred planning', meaning that all efforts must be made to include the views of the person with the disability in the decision-making about needs and futures, so that these individuals have choice in their lives. It is important that this choice extends to all domains of life, including the basic human right to have a reasonable social and family life (Human Rights Act 1998). It is also important that choice is properly informed. This does not mean simply telling learning-disabled people what is currently provided by local services; it also means ensuring that they understand their rights and options, and helping them to decide how they want to live their lives. For a person with a learning disability, separation from family, from long-held attachments and from loved ones is a major life event that might precipitate a range of mental disorders and behaviours that must be understood and managed sensitively (Stack et al, 1987).

Professionals working in the field of learning disabilities are reported to have patronising attitudes, with a tendency to assume that they know what is best (Nursey et al, 1990). Very often we try to persuade or direct individuals to accept what is on offer, even though this may fall far short of meeting their wishes and their need to be close to family. This has particular relevance for Black and minority ethnic groups, who are frequently separated from their communities, and for those who have complex needs requiring a high degree of interagency coordination. The importance of family, culture and values to someone with a learning disability must not be underestimated or denied.

A large number of people with learning disabilities have diminished capacity to understand their rights
Box 2 How to help individuals with learning disabilities to make an informed choice

- Give information in small chunks

- Speak in simple and non-technical language

- Use communication tools such as picture books

- Ask family members, carers or advocates to help to communicate information

- Make sure that the individual has actually understood what has been said

and articulate their viewpoint. These issues have been well addressed in the government Green Paper Who Decides? (Lord Chancellor's Department, 1997), which highlights the importance of family members and immediate carers in decision-making. The role of advocates may be crucial, especially if there are differences in opinion between the learning-disabled individual and the parents. Some of the ways in which professionals can help people with learning disabilities to make informed choice are listed in Box 2.

Just being near family or living in an ordinary street does not necessarily lead to true community integration. The measurement of quality of life is complex and highly personal (Felce, 1999). An individual placed in an out-of-borough residential home can have a good quality of life and may choose to live there. The arguments in favour of rural quietness for some people do have validity, as do the arguments in favour of residential communities. The issue for the individual is choice and how that choice is made.

\section{Parents}

When parents describe the kind of living arrangements they would like to see available for their son or daughter, one characteristic is always mentioned: it must be a 'home'. The need for a caring, secure and permanent environment, which takes a highly personalised approach, is fundamental to parents' wishes. Parents are largely agreed on a number of determining features of a homely environment: it should be small in size; the atmosphere should give a sense of being accepted; there should be adequate staffing and supervision; and the needs of the residents should come before those of the staff and of the organisation (Richardson \& Ritchie, 1989). Parents have also lobbied for supported-living arrangements that allow learning-disabled individuals to live alone or with a similarly disabled friend (Fitton et al, 1995).

The exploration of parental views by Richardson \& Ritchie (1989) suggests that most parents believe 
their choices to be confined to what is locally available. Some parents know little about residential provision, whereas others are well informed through the local voluntary bodies such as Mencap (http:// www.mencap.co.uk). Parents groups such as RESCARE (http://www.rescare.org.uk) often have very strong views and lobby for specific types of provision.

Parents' views on making the break from their disabled child are highly complex. Some actively seek residential placements for their offspring, believing that it is in everyone's interests for them to gain independence from the family; some cannot contemplate a move at all, believing that paid carers could never replace parental love and concern; some are deeply ambivalent about these decisions, which causes great anxiety (Richardson \& Ritchie, 1986). These difficulties are more manageable if the parents feel involved in the decision-making and in the ongoing care of their child. Professionals often consider parental views as overprotective, and see it as their role to champion the needs of the child against the parent. Although this may be necessary in a small number of enmeshed relationships, such an approach can increase the difficulties experienced by both child and parents at a time of great anxiety.

Out-of-borough placements, unless clearly chosen by parents and child, will increase parental concerns; they will find it more difficult to manage the ambivalent feelings associated with the move, as they will have less control, less involvement and will be unable to monitor closely their child's welfare. This can lead to anger about the lack of services; such anger needs to be understood and worked through, but it is easily swept aside by professionals who see it as a demonstration of pathology.

There may be times when the views of parents appear to contradict the views of their offspring. Such situations need careful management. Proper assessment of the abilities, understanding and motives of both parties is necessary. Both the child and the parents might benefit from the support and advice of their own advocates.

\section{Local authorities}

Local authorities have become the lead agency for learning disability services, and in some areas this includes the management of health professional teams. The system of care management has become well established, theoretically allowing micromanagement of individual care packages (Department of Health, 1989) so that resources can be used to the best advantage of the individual. One of the critical management responsibilities is the purchasing of residential care in, for example, hostels, staffed homes, and residential care homes run by either local authorities, voluntary organisations or private bodies.

For people with learning disabilities who have complex needs, out-of-borough residential care is often seen as the only option, on grounds both of costs and suitability. Despite the urgings of the 2001 White Paper, in many areas there appears to be reluctance to consider local supported-living arrangements for people with behavioural or mental health problems. Among the reasons generally cited are a lack of adequate local accommodation and support services; fears about potential risks to the community; and costs and cost-benefit analyses (Ryan, 1998). However, assumptions about the comparative costs of residential and supported community living may be unsound. Distant residential placements may cost less in the short term, but can be more costly in the longer term, as well as being less popular with learning-disabled people and their families and difficult for the exporting authority to monitor (Collins, 1994).

Residential care, where accommodation and support come as a package, offers a convenient 'offthe-shelf' solution to purchasers seeking urgent accommodation for people with challenging needs. Purchasers perceive the risks and commitment to local supported-living packages as too high and are prepared to pay over the odds for residential care for those most challenging simply to resolve the problem, and their partner NHS trusts are often happy to agree (Ryan, 1998).

Local authorities have a responsibility to provide full-time education to all children with learning disabilities up to the age of 19. Although most of these children will receive education within the borough, those with very complex needs, particularly those with difficult behaviours and those with pervasive developmental disorders, may be placed in residential schools outside the borough. Their return to the borough at the age of 19 requires good joint planning based on needs and service provision; failure of such planning may lead to a person remaining out of borough against the wishes of the individual and the family.

\section{Health services}

Health services vary greatly in their composition across the country, some still providing residential care. Bailey \& Cooper (1998) found that, on average, NHS trusts managed 10.3 long-stay beds per 100000 population, but that $20 \%$ of trusts had no long-stay NHS provision at all for people with learning disabilities. A further $40 \%$ of NHS trusts had completed their resettlement process, but retained 
some NHS long-stay beds, having reprovided these within small community units directly managed by NHS trusts.

These authors also report that the majority of NHS trusts provided assessment and treatment beds and all provided community teams for learning disability (CTLDs), although the professional makeup of these teams varied very greatly between services. The implementation of the National Service Framework for Mental Health (Department of Health, 1999) as it relates to people with learning disabilities also varies around the country. In some areas the learning disability services have representatives on the National Service Framework implementation teams, in others they have yet to achieve this.

Valuing People promotes closer integration with general psychiatry to meet the mental health needs of people with learning disabilities, but in many areas general psychiatric services are still reluctant to see these individuals. A good relationship with general psychiatry seems essential for robust mental health services for learning-disabled people.

There is a strong clinical impression that, where local assessment and treatment services do not exist and where CTLDs are not well resourced, there is a much greater use of out-of-borough placements as a way of solving a crisis, but that this often fails to help the individual with their mental disorder. Even where there are good assessment and treatment facilities, if there are no local residential services for people with mental health disorders then an out-ofborough placement may be the only way to prevent hospital bed-blocking. Our experience is that many psychiatrists working in exporting boroughs experience conflicts and frustrations because of an inability to practise appropriately.

The problems faced by the health services in importing boroughs centre on stretching limited resources to meet an unpredicted influx. It is not uncommon for a learning-disabled person to be placed in a private residential home and simply registered with a general practitioner. The first the local mental health team knows of the placement is when the general practitioner refers at a time of mental health crisis. There is guidance that the placing local authority must ensure that the individual's health needs can be met (Department of Health, 1989), but how this is to be enforced is not clear.

There is also a small but significant group of learning-disabled people with mental health problems defined as needing continuing health care. With the reduction in the health service role, it is hard to provide continuing health care within the local area, and most placements of this type appear to be in a growing private hospital sector.

\section{Implications for clinicians}

Clinicians are always pressurised by the need for acute-admission beds. Although discharging patients from hospital should depend on a clinical decision, it does not always do so. One important factor affecting the decision is the availability of local services that can adequately meet the care needs of the individual and manage the risks involved. If a suitable care package is not available locally then invariably the only other option is to consider out-of-borough placement.

As mentioned above, out-of-borough placement is usually not the most popular choice with families, professionals or individuals. Problems also result from lack of communication of needs and risks between various professional agencies. Therefore, before considering any such placement, clinicians should ensure that there is an open discussion with the family and the individual concerned and that their wishes are taken into consideration. Advocacy can play a useful role in such meetings. If an outof-borough placement is necessary, the service providers should be properly informed of the individual's needs and risk; cost and funding issues must be resolved before the move; and a care plan must be agreed by both the importing and exporting authority through the care programme approach.

\section{The planning role}

The work of a consultant psychiatrist in learning disabilities cannot finish with the patient's treatment plan. A whole-system approach means that psychiatrists should know what is planned and what is possible in the system, so that they can advise patients and their carers appropriately. If psychiatrists become aware of unmet needs they must know to whom they should communicate this information.

Membership of joint commissioning boards is an important role for a senior clinician, but practice is quite varied around the country. As in clinical services, no standard or benchmark has been established.

Good working relationships with senior managers in the health and social services as well as with those in the voluntary and private sectors allow clinicians to use their influence to avoid unnecessary conflict, thus encouraging service development. Community learning disability services should be tracking learning-disabled people who show challenging behaviour, as well as those about to leave school and in out-of-borough placements. Through the joint commissioning board forum it is possible to raise issues regarding local needs for 
acute beds, for medium-stay rehabilitation and for continuing health care, as well as to discuss the community resources necessary to support people locally in specialist housing.

\section{Implications for specialist registrar training}

There are such wide variations between services that a specialist registrar who has trained mostly in an area that exports learning-disabled people with mental disorders may find it hard to work as a consultant in an area that imports people with complex needs. Training scheme organisers should therefore try to include positions with both importers and exporters in the rotations.

Specialist registrars should have a good grasp of joint commissioning, of the reasons for resource variations and of the pressures experienced by staff in different agencies. This can be effected through placements in these agencies and interprofessional training. The trainee must develop a whole-system understanding.

Conflicts arising from the difficult decisions to be made, the angst of parents, and the issues of risk and resources often spill into the workplace. This raises the specific need to learn conflict-resolution skills.

\section{Conclusions}

The goal of current government policy is to ensure that every person with a learning disability has the opportunity and support required to live an 'ordinary life' in the community, and that these are tailored to meet their individual needs and wishes. However, for historical, political and economic reasons there is wide diversity in the availability of services across UK. Owing to the agendas of the different stakeholders, there is sometimes ambivalence about the best way forward. Some of these issues are addressed in the policy proposal in Box 3.

Clinicians need to find realistic solutions in their day-to-day clinical practice. They deal with a very diverse population requiring services of different types and, until all of these services are available locally, they need to manage within-borough and out-of-borough resources to get optimum benefit for patients.

There is still a need for much research in this field, and learning-disabled individuals and their families and carers should be involved in the research agenda. Following deinstitutionalisation, research focused mainly on the quality of life of people with learning disabilities and on their community presence, comparing community with institutional placements (Cullen et al, 1995). However, community presence does not necessarily equal community integration. Both 'community integration' and 'quality of life' are abstract concepts, difficult to define and measure. However, a way must be found both to define these concepts in relation to people with learning disabilities and to measure them against the 'ideal norm' that is considered acceptable for the general population and is set down in the National Service Frameworks. Only then can a true 'ideal norm' for learning disability also be set in government policy. And it is essential that learning-disabled people and their families be involved in this process.

There is a need to understand more fully the reasons behind out-of-borough placements and the causes and consequences of the huge variations in services. Research and audit could also examine issues such as the impact of joint commissioning on policy formation, decision-making and the process of transfer between services.

The mental institutions are by and large closed, but the new community services still need much research and development. We must not neglect the new group of people who are being left out of society.

\section{Box 3 A policy proposal}

A possible policy approach would be for the specialist health needs of a learning-disabled person to remain the responsibility of the primary care trust of origin. Any placement out-of-borough would need a joint commissioning approach, with full assessment of health and social needs. The importing districts would bill the exporting primary care trust for any specialist health input.

The Care Standards Commission has a monitoring role, as defined in the Care Standards Act 2000, Chapter 14, to ensure that private providers have realistic health action plans for all their residents, which allows changes in specialist health needs to be tracked.

With a reasonable income for the importing district for the service provided, there is less drain on resources available to local people. With the exporting authorities having to meet all the costs, the development of local services will be encouraged. 


\section{References}

Bailey, N. M. \& Cooper, S. A. (1998) The current provision of specialist health services to people with learning disabilities in England and Wales. Journal of Intellectual Disability Research, 41, 52-59.

Collins, J. (1994) Still to be Settled: Strategies for the Resettlement of People from Mental Handicap Hospitals. London: Value in Action.

Cullen, C., Whoriskey, M., Mackenzie, K., et al (1995) The effect of deinstitutionalisation on adults with learning disabilities. Journal of Intellectual Disability Research, 39, 484-494.

Department of Health and Social Security (1979) Report of the Committee of Enquiry into Mental Handicap Nursing and Care. $\mathrm{Cm}$ 7468. London: HMSO.

Department of Health (1989) Caring for People. Community Care in the Next Decade and Beyond. London: HMSO.

Department of Health (1999) National Service Framework for Mental Health. Modern Standards and Service Models. London: Department of Health.

Department of Health (2001) Valuing People: A New Strategy for Learning Disability for the 21st Century (Cm 5086). London: Department of Health.

Department of Health (2002) Health and Personal Social Services Statistics: England. Section B: Health Care. Table B22 Mental health and learning disability: hospital beds and places in residential and nursing care homes for people with learning disabilities. London: Stationery Office. http:// www.doh.gov.uk/HPSSS/TBL_B22.HTM

Department of Health (2003) Community Care Statistics 2003. Supported Residents (Adults), England. London: Department of Health. http://www.doh.gov.uk/public/sb0319.pdf

Department of Health and Social Security Welsh Office (1971) Better Services for the Mentally Handicapped. London: HMSO.

Emerson, E. \& Hatton, C. (1998) Residential provision for people with intellectual disabilities in England, Wales and Scotland. Journal of Applied Research in Intellectual Disabilities, 1, 1-14.

Felce, D. (1999) The Gerry Simon Lecture, 1998: Enhancing quality of life of people receiving residential support. British Journal of Learning Disabilities, 27, 4-9.

Fitton, P., O'Brien, C. \& Wilson, J. (1995) Home at Last: How Two Young Women with Profound Intellectual and Multiple Disabilities Achieved their Own Home. London: Jessica Kingsley.

Foster, A. \& Roberts, V. Z. (1998) 'Not in my backyard': the psychosocial reality of community care. In Managing Mental Health in the Community: Chaos and Containment (eds A. Foster \& V. Z. Roberts), pp. 27-37. London: Routledge.

Holt, G., Costello, H., Bouras, N., et al (2000) BIOMEDMEROPE project: service provision for adults with intellectual disability: a European comparison. Journal of Intellectual Disability Research, 44, 685-696.

King's Fund (1980) An Ordinary Life: Comprehensive LocallyBased Residential Services for Mentally Handicapped People. London: King's Fund.

Lord Chancellor's Department (1997) Who Decides? Making Decisions on Behalf of Mentally Incapacitated Adults. London: HMSO.

Lowe, K. \& de Paiva, S. (1991) NIMROD: An Overview. London: HMSO.

Myers, F., Ager, A., Kerr, P., et al (1998) Outside looking in? Studies of community integration of people with learning disabilities. Disability and Society, 13, 389-413.

National Health Service Executive (2000) London Learning Disability Strategic Framework. Service Mapping Feedback Report. London: NHS Executive.

Nursey, A. D., Rhode, J. R. \& Farmer R. D. (1990) A study of doctors' and parents' attitude to people with mental handicaps. Journal of Mental Deficiency Research, 34, 143-155.

Radford, J. P. (1991) Sterilization versus segregation: control of the 'feebleminded', 1900-1938. Social Science and Medicine, 33, 449-458.

Richardson, A. \& Ritchie, J. (1986) Making the Break: Parents' Views about Adults with a Mental Handicap Leaving Home. London: King's Fund.
Richardson, A. \& Ritchie, J. (1989) Letting Go: Dilemmas for Parents Whose Son or Daughter Has a Mental Handicap. Milton Keynes: Open University Press.

Royal Commission (1957) The Law Relating to Mental Illness and Mental Deficiency 1954-1957. Report. London: HMSO.

Ryan, T. (1998) Lost opportunities: purchasing strategies in housing and support for people with learning difficulties. Mental Health Care, 1, 296-299.

Stack, L. S., Haldipur, C. V. \& Thompson, M. (1987) Stressful life events and psychiatric hospitalisation of mentally retarded patients. American Journal of Psychiatry, 144, 661-663.

\section{Multiple choice questions}

1 The government White Paper Valuing People:

a sets out new strategies for people with learning disabilities

b proposes that all learning-disabled people, irrespective of their level of abilities, should have a choice as to where they want to live

c recommends that health services should provide residential care for people with learning disabilities

d sets out objectives for community integration of people with learning disabilities

e proposes an increase in the range and choice of housing open to people with learning disabilities.

2 Local authorities:

a are responsible for providing and purchasing residential care for people with learning disabilities

$\mathrm{b}$ tend to prefer residential care over supported-living arrangements for these people

c may perceive the risks and commitments to local supported-living packages as being too high

d do not manage community learning disability teams

e are responsible for providing full-time education to children with severe learning disabilities until the age of 19 years.

3 As regards living arrangements for individuals with learning disabilities:

a their parents are usually reluctant to become involved in the decision-making process

$\mathrm{b}$ some parents are ambivalent about any move of a son or daughter into residential care

c most parents are well informed of the choices available

d parents' views should override the views of their offspring

e living in an ordinary street always leads to true community integration.

4 With regards to residential accommodation available to people with learning disabilities:

a supported living cannot be used for individuals with severe learning disabilities

b hostels run by local authorities are a form of supported living

c residential care homes are always run by local authorities

d residential care homes are better than supported community living 
e the majority of learning-disabled people live with their parents.

5 People with learning disabilities:

a are not competent to decide where they should live

b should contribute to research development

c can access similar services in all parts of the country

$\mathrm{d}$ have always been stigmatised

e do not experience grief at losing contact with significant attachment figures.

\section{MCQ answers}

\begin{tabular}{|c|c|c|c|}
\hline 1 & 2 & 3 & 4 \\
\hline a $\mathrm{T}$ & a $\mathrm{T}$ & a F & a F \\
\hline b $\mathrm{T}$ & b $\mathrm{T}$ & b $\mathrm{T}$ & b F \\
\hline$c F$ & c $\mathrm{T}$ & c F & C F \\
\hline d $\mathrm{T}$ & d F & d F & d F \\
\hline e $\mathrm{T}$ & e $\mathrm{T}$ & e $F$ & e $\mathrm{T}$ \\
\hline
\end{tabular}

\section{The Royal College of Psychiatrists}

\section{CONFERENCES}

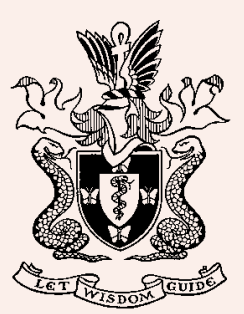

\section{DATE}

4-5 March

$17-19$ March

1 April

$22-24$ April

6-7 May

$6-9$ July

$20-22$ Sep

30 Sep -1 Oct

$14-15$ Oct

$11-12$ Nov

\section{FACULTY}

Faculty of Old Age Psychiatry Annual Meeting

Section of Liaison Psychiatry Annual Meeting

Faculty of the Psychiatry of Learning Disability Spring Meeting

Faculty of Psychotherapy Annual Meeting

Faculty of Substance Misuse Annual Meeting

Annual Meeting 2004

Faculty of Child and Adolescent Psychiatry Annual Meeting

Faculty of Learning Disability Annual Meeting

Faculty of General and Community Psychiatry Annual Meeting

Section of Rehabilitation and Social Psychiatry Annual Meeting

\section{LOCATION}

Crowne Plaza, Liverpool

Crowne Plaza, Cambridge

Regent's College, London

Ardoe House, Aberdeen

Thistle Hotel, Glasgow

Harrogate

International Centre

Edinburgh Conference Centre

Radisson Hotel, Glasgow

University Arms, Cambridge

Monkbar Hotel, York

To see programmes, other information and to book online, visit: www.rcpsych.ac.uk/conferences 